\title{
Cross-sectional description of nursing and midwifery pre-service education accreditation in east, central, and southern Africa in 2013
}

Carey F. McCarthy ${ }^{1 *}$, Jessica M. Gross ${ }^{1}$, Andre R. Verani ${ }^{1}$, Annette M. Nkowane ${ }^{2}$, Erica L. Wheeler ${ }^{3}$, Thokozire J. Lipato ${ }^{4}$ and Maureen A. Kelley ${ }^{5}$

\begin{abstract}
Background: In 2013, the World Health Organization issued guidelines, Transforming and Scaling Up Health Professional Education and Training, to improve the quality and relevance of health professional pre-service education. Central to these guidelines was establishing and strengthening education accreditation systems. To establish what current accreditation systems were for nursing and midwifery education and highlight areas for strengthening these systems, a study was undertaken to document the pre-service accreditation policies, approaches, and practices in 16 African countries relative to the 2013 WHO guidelines.
\end{abstract}

Methods: This study utilized a cross-sectional group survey with a standardized questionnaire administered to a convenience sample of approximately 70 nursing and midwifery leaders from 16 countries in east, central, and southern Africa. Each national delegation completed one survey together, representing the responses for their country.

Results: Almost all countries in this study $(15 ; 94 \%)$ mandated pre-service nursing education accreditation However, there was wide variation in who was responsible for accrediting programs. The percent of active programs accredited decreased by program level from $80 \%$ for doctorate programs to $62 \%$ for masters nursing to $50 \%$ for degree nursing to $35 \%$ for diploma nursing programs. The majority of countries indicated that accreditation processes were transparent (i.e., included stakeholder engagement (81\%), self-assessment (100\%), evaluation feedback (94\%), and public disclosure (63\%)) and that the processes were evaluated on a routine basis (69\%). Over half of the countries (nine; 56\%) reported limited financial resources as a barrier to increasing accreditation activities, and seven countries (44\%) noted limited materials and technical expertise.

Conclusion: In line with the 2013 WHO guidelines, there was a strong legal mandate for nursing education accreditation as compared to the global average of $50 \%$. Accreditation levels were low in the programs that produce the majority of the nurses in this region and were higher in public programs than non-public programs. WHO guidelines for transparency and routine review were met more so than standards-based and independent accreditation processes. The new global strategy, Workforce 2030, has renewed the focus on accreditation and provides an opportunity to strengthen pre-service accreditation and ensure the production of a qualified and relevant nursing workforce.

\footnotetext{
* Correspondence: cfmccart@gmail.com

'Health Systems and Human Resources Team, Division of Global HIV/TB, U.S.

Centers for Disease Control and Prevention, Atlanta, GA, United States of

America

Full list of author information is available at the end of the article
} 


\section{Background}

The 2006 World Health Assembly called for an unprecedented scale-up of health worker training [1]. Among the global responders was the US President's Emergency Plan for AIDS Relief (PEPFAR) with a commitment to support the training and retention of 140000 new healthcare workers, primarily in sub-Saharan Africa [2-5]. Subsequent global policy documents from the World Health Organization (WHO) echoed the need to increase the number of health workers but also to ensure new health workers are part of a skilled and competent workforce that can promote universal access to health services, including antiretroviral therapy (ART) to treat and prevent human immunodeficiency virus (HIV) transmission $[2,6,7]$. The landmark Lancet Commission Report (2010), Health professionals for a new century: transforming education to strengthen health systems in an interdependent world, identified accreditation of health professional education institutions as an essential prerequisite for quality health professional education [8]. Lastly, the WHO Global Strategy on Human Resources for Health: Workforce 2030 identified accreditation mechanisms for health training institutions as a milestone to be achieved by all countries by the year 2020 [9].

The World Federation for Medical Education (WFME) defines accreditation as "a process of review and approval by which an institution or program is granted a timelimited recognition of having met certain established standards" [10]. Accreditation can be an effective tool aligning health professional education with population health needs to ensure new graduates have the relevant competencies and skills to address current public health requirements [11]. In doing so, accreditation systems can also help strengthen social accountability in national health professional education [12, 13]. Innovative approaches in health professional education, and a growing demand for accountability and quality assurance in higher education, have contributed to a stronger focus on accreditation worldwide [8]. However, less than half of the countries globally have a comprehensive accreditation system that is credible and transparent; most have systems where programs and schools are either not reviewed or reviews are conducted on an ad hoc basis [14].

In 2013, WHO, released guidelines for transforming and scaling up health professional education and training [11]. The guidelines set out a vision for increasing the quantity, quality, and relevance of health professionals and provide recommendations on how to produce health professional graduates equipped to meet the needs of the communities they serve [11]. "Accreditation and regulation" is one of the five domains of the guidelines. A specific recommendation is for governments to introduce or strengthen health professional education accreditation [11]. Key considerations for governments include ensuring the accreditation process is transparent, based on standards, supported by legislation and undertaken independently, and that the process is periodically evaluated [14]. According to WHO policy briefs developed as part of the guideline process, carrying out successful accreditation requires the requisite human, material, and financial resources, as well as periodic evaluation of the system itself [14]. The systems need to be legally legitimate with the authority to accredit and sanction, ensuring that the accreditation process is efficient and includes at the very least a self-assessment, external review, site visit, and assessment report [14]. To effectively monitor national accreditation practices, WHO recommends data collection by the professional regulatory bodies, such as accrediting agencies or health professional councils, employers, and health professional training institutions [11].

While country-level reviews of pre-service nursing education in the African region have been published [15], there has not yet been a systematic assessment of nursing and midwifery pre-service accreditation in the East, Central, and Southern Africa (ECSA) region. This study sought to gain an understanding of current pre-service accreditation policies, approaches, and practices in 16 ECSA countries relative to the 2013 WHO guidelines, Transforming and Scaling Up Health Professional Education and Training.

\section{Methods}

This study utilized a cross-sectional group survey with a standardized questionnaire administered to a convenience sample of approximately 70 nursing and midwifery leaders from 16 countries in attendance at the PEPFARsupported African Health Profession Regulatory Collaborative (ARC) [16-18] forum from July 30 to August 2, 2013, in Nairobi, Kenya. The countries represented at the ARC meeting included Botswana, Ethiopia, Kenya, Lesotho, Malawi, Mauritius, Mozambique, Namibia, Rwanda, Seychelles, South Africa, South Sudan, Swaziland, Tanzania, Uganda, Zambia, and Zimbabwe. For each country, the leaders included the chief nursing officer in the ministry of health, registrar of the nursing and midwifery council, head of the professional nursing and midwifery association, and a representative from a nursing or midwifery academic institution. Incentives were not provided to participate in the study.

Data were collected using a standardized survey (Additional file 1) developed by the authors in 2013. Survey questions included the number and level of pre-service nursing and midwifery training schools or programs and the systems, approaches, and mechanisms of accreditation of pre-service nursing and midwifery education, as well as the challenges associated with accrediting nursing and midwifery training programs. Each country delegation of nursing leaders 
completed one survey together, representing the responses for their country (i.e., a group survey). A group survey was deemed superior to an individual survey to avoid the possibility of missing or conflicting information within the same country. Surveys were administered and completed in English for all countries, including the Mozambican group which was assisted by a professional Portuguese-English translator. The survey included closedchoice questions with comment boxes for the choice of "other," Likert scale questions, and open-ended questions with special instructions for what participants should do if there is no consensus among group members on a particular response. The U.S. Centers for Disease Control and Prevention reviewed and approved the study protocol.

The surveys were identified by country; professional positions represented by survey respondents were noted. All the data were entered and stored in a password-protected database to facilitate confidentiality and consistent analysis by select co-authors across countries. Missing data or data requiring verification were collected during the conference or via email to ensure the completeness and trustworthiness of the data for analysis. Each individual country served as the unit of analysis, providing a composite description of the nursing and midwifery pre-service training programs, the accreditation systems and approach, and country-level accreditation challenges faced by nursing regulatory bodies. The definition of accreditation used on the survey was the following: "A process of review and approval by which an institution is granted time-limited recognition of having met certain established standards" [9]. Midwifery programs are defined as midwifery-only programs. Ethiopia, Mozambique, and South Africa's nursing and midwifery programs and Tanzania's certificate, diploma, post-basic, and degree programs were excluded from the accreditation status analysis due to missing data.

\section{Results}

Survey responses represented 16 countries, as South Sudan did not participate in the study, with highly variable numbers of nurses in the country, from over 500 nurses per 100000 population (South Africa) to about 25 per 100000 (Ethiopia), and a range of program options by country, from basic certificate to an advanced $\mathrm{PhD}$ (Table 1). Countries also varied in the number of nursing and midwifery training institutions, from six in Swaziland and the Seychelles to over 100 in Kenya. The greater the number of schools in a country, the more likely they were to have non-public (i.e., private or faithbased) nursing schools as an option for pre-service education, with the exception of Swaziland and Malawi that had relatively few schools, of which $50 \%$ were nonpublic ( $n=3$ and $n=8$, respectively). Countries in which the majority of schools were public (i.e., government), such as Botswana, Namibia, Rwanda, and Zambia, reported the highest levels of accreditation. Uganda and Zimbabwe reported 100\% accreditation of schools across public and non-public institutions. Kenya, Mozambique, and Seychelles reported accreditation levels too low to cover even the public schools.

Country teams were asked whether accreditation was mandatory, where it was mandated in policy, and which bodies conducted the accreditation. Investigators then consulted the primary sources listed to find national health laws and policies addressing accreditation (Table 2). Accreditation of pre-service nursing and midwifery training institutions was mandated in 15 of the countries surveyed (94\%). The nursing council served as the sole accrediting body in five countries, including Kenya, Malawi, South Africa, Zambia, and Zimbabwe. Accreditation was a shared responsibility with another entity in four countries, such as an education council in Lesotho, an independent qualification authority in Namibia and the Seychelles, and the Ministry of Health and Ministry of Education in Uganda. The Ministry of Education accredited nursing institutions in Ethiopia and Rwanda, whereas Mauritius and Swaziland used independent authorities. Botswana and Tanzania relied on educational councils. The mandate for the accreditation of nurse training institutions was located in the national nurses and midwives act for 12 of the 16 countries surveyed (75\%).

The reported approaches and processes for accrediting nursing and midwifery institutions varied across countries (Fig. 1). The approach typically involved an institutional self-assessment (16 countries) and the use of external inspectors (15 countries). Eleven countries (69\%) used an independent board to review the internal and external assessments and make the accreditation decision. Four countries (25\%) utilized self-assessment and external inspection without an independent board review. Fifteen countries (94\%) provided feedback to programs and schools regarding their accreditation evaluations. The accreditation processes varied. In 14 countries, different levels of accreditation were granted; 13 countries involved stakeholders in the process; and 10 countries required nursing and midwifery programs to renew their accreditation, yet it was only enforced in seven of the countries. Twelve countries (86\%) reported their accreditation process was based on standards, with 10 countries using national standards, three using regional standards, and one using international standards.

The proportion of programs accredited varied across program levels and types (Table 3 ). The percentage of accreditation for active nursing programs decreased by program level from $80 \%$ for doctorate programs to $62 \%$ for masters nursing to $50 \%$ for degree nursing to $35 \%$ for diploma nursing programs. Diploma nursing programs represented $37 \%$ of the reported 350 active programs; however, only $35 \%$ of diploma nursing programs were accredited. 


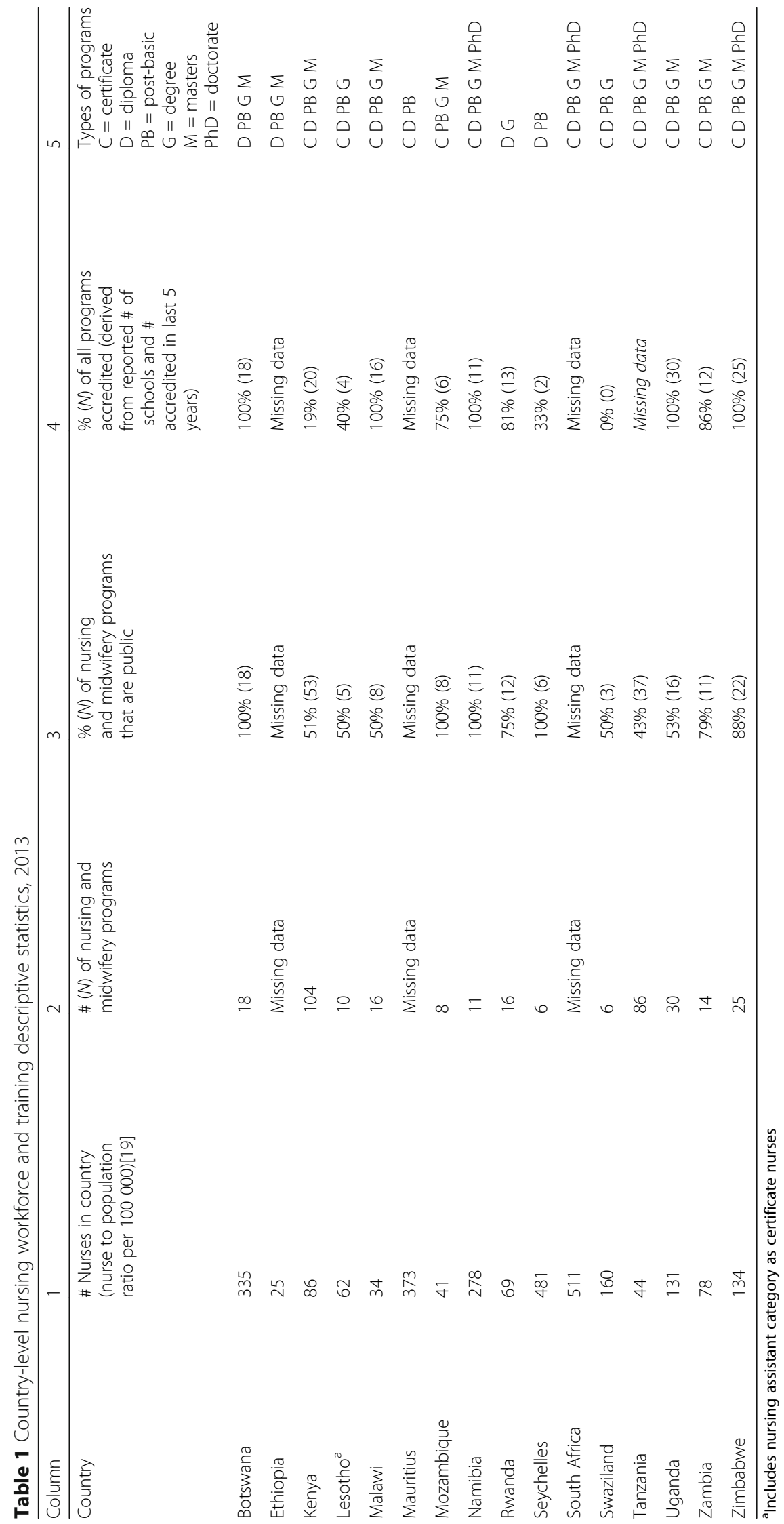




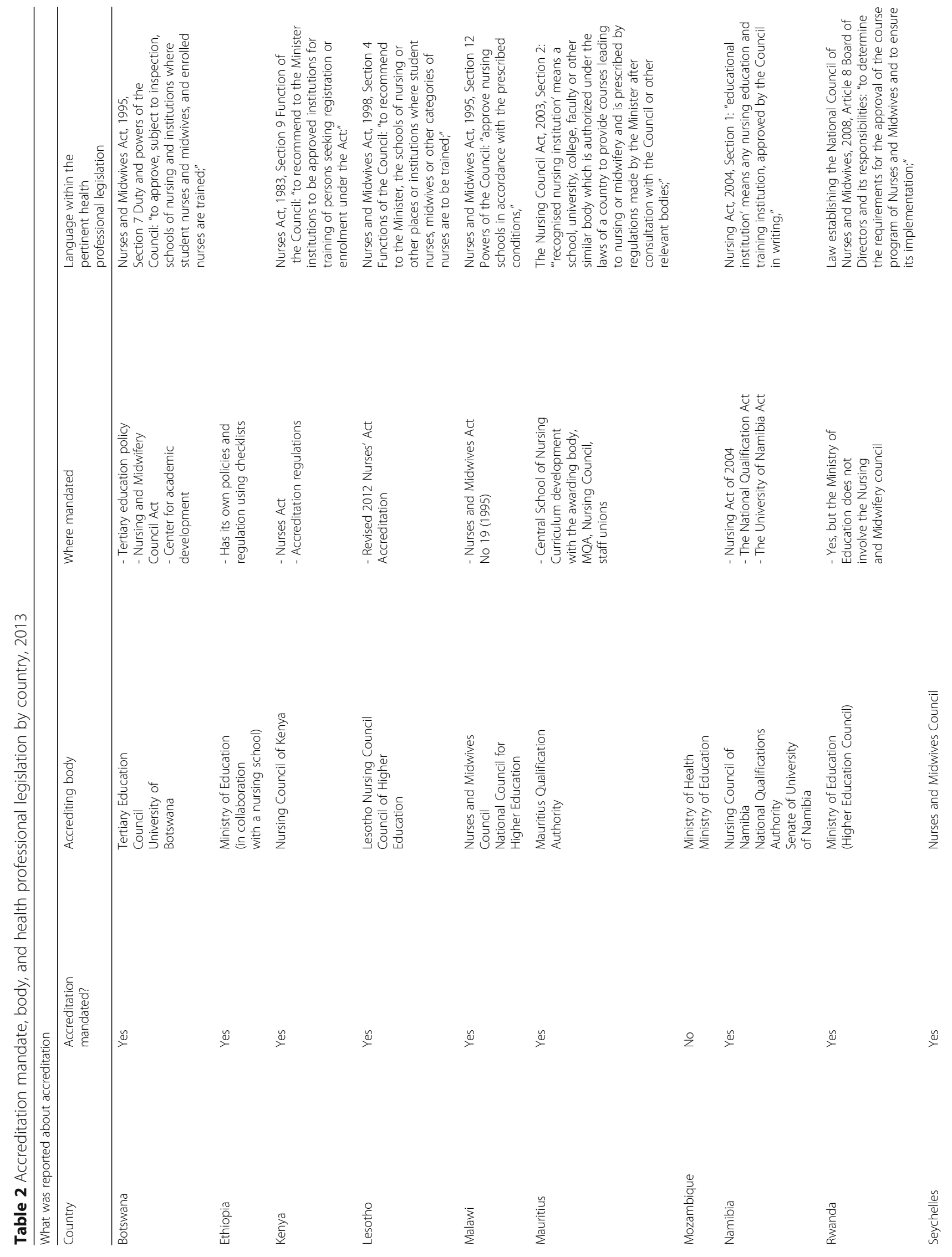




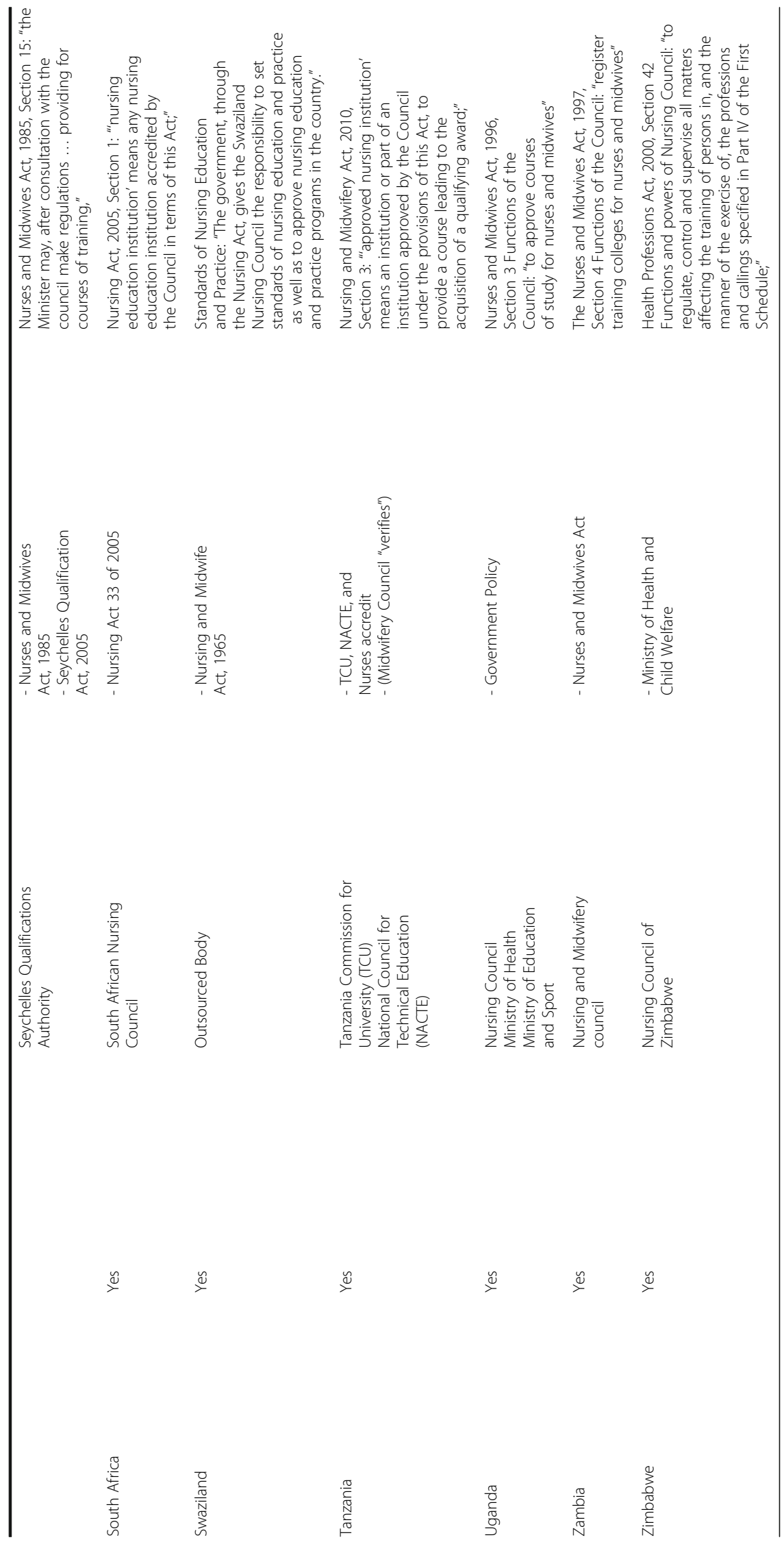




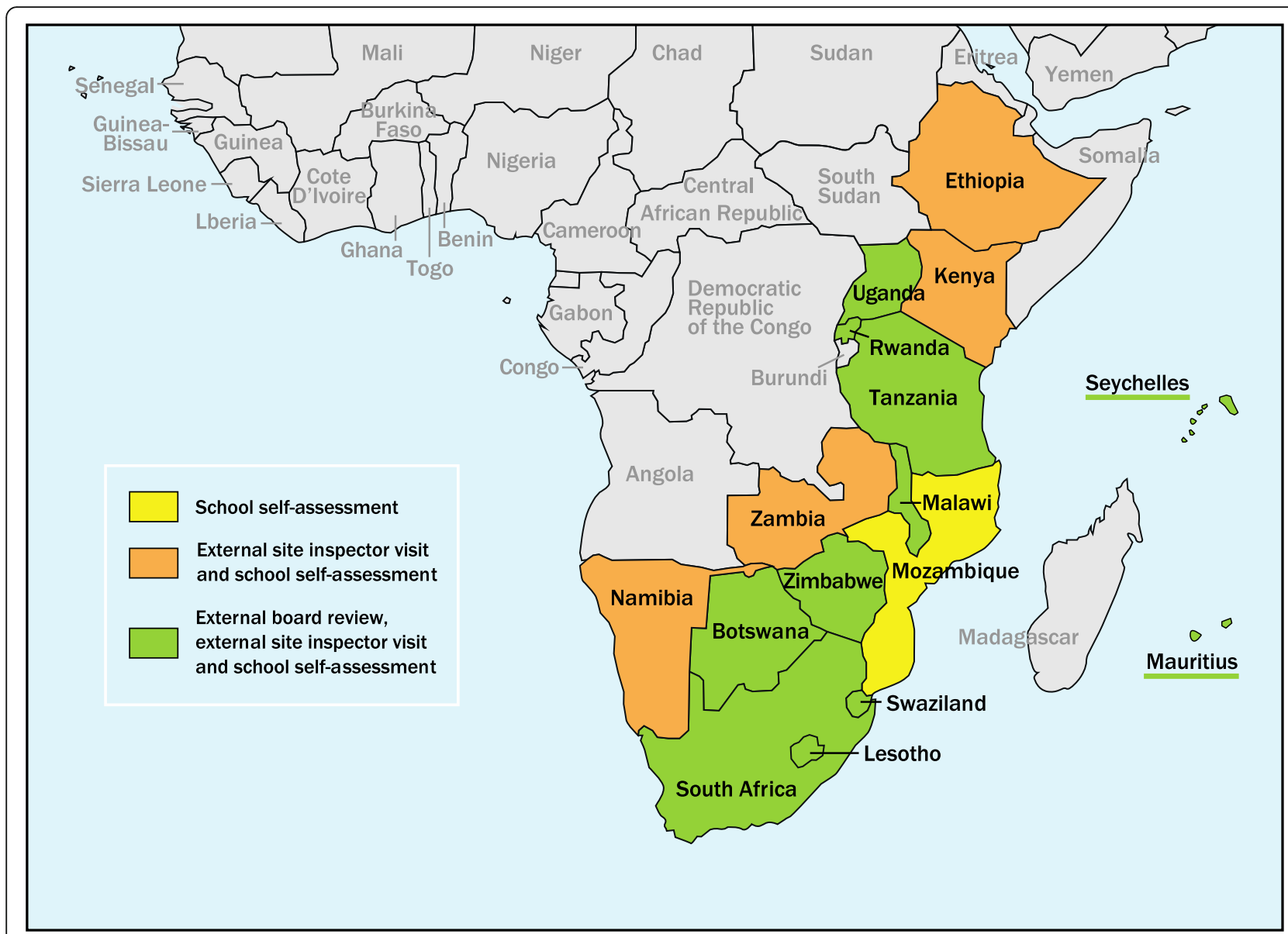

Fig. 1 Accreditation process by country, 2013

Table 3 Duration, number, and accreditation status of nursing and midwifery programs by level, 2013

\begin{tabular}{|c|c|c|c|c|c|c|}
\hline Program Level & $\begin{array}{l}\text { Average } \\
\text { Duration } \\
\text { (months) }\end{array}$ & $\begin{array}{l}\text { \# Countries } \\
\text { with program } \\
(n=13)\end{array}$ & $\begin{array}{l}\text { \# Active } \\
\text { Programs }\end{array}$ & $\begin{array}{l}\% \text { Active } \\
\text { Accredited }\end{array}$ & $\begin{array}{l}\% \text { Public } \\
\text { Accredited }\end{array}$ & $\begin{array}{l}\text { \% Private } \\
\text { Accredited }\end{array}$ \\
\hline $\begin{array}{l}\text { Certificate Nursing } \\
\text { Certificate Midwifery }\end{array}$ & $\begin{array}{l}23 \\
23\end{array}$ & $\begin{array}{l}8 \\
4\end{array}$ & $\begin{array}{l}49 \\
14\end{array}$ & $\begin{array}{r}81 \\
100\end{array}$ & $\begin{array}{r}73 \\
100\end{array}$ & $\begin{array}{l}100 \\
100\end{array}$ \\
\hline $\begin{array}{l}\text { Diploma Nursing } \\
\text { Diploma Midwifery }\end{array}$ & $\begin{array}{l}36 \\
29\end{array}$ & $\begin{array}{r}12 \\
3\end{array}$ & $\begin{array}{r}131 \\
11\end{array}$ & $\begin{array}{l}35 \\
91\end{array}$ & $\begin{array}{l}44 \\
88\end{array}$ & $\begin{array}{r}24 \\
100\end{array}$ \\
\hline $\begin{array}{l}\text { Post-basic Nursing } \\
\text { Post-basic Midwifery }\end{array}$ & $\begin{array}{l}19 \\
17 \\
\end{array}$ & $\begin{array}{c}11 \\
8 \\
\end{array}$ & $\begin{array}{l}58 \\
14 \\
\end{array}$ & $\begin{array}{l}82 \\
71 \\
\end{array}$ & $\begin{array}{l}80 \\
82 \\
\end{array}$ & $\begin{array}{l}90 \\
33 \\
\end{array}$ \\
\hline $\begin{array}{l}\text { Degree Nursing } \\
\text { Degree Midwifery }\end{array}$ & $\begin{array}{l}45 \\
48 \\
\end{array}$ & $\begin{array}{r}12 \\
3 \\
\end{array}$ & $\begin{array}{r}46 \\
3 \\
\end{array}$ & $\begin{array}{r}50 \\
100 \\
\end{array}$ & $\begin{array}{r}58 \\
100 \\
\end{array}$ & $\begin{array}{r}33 \\
- \\
\end{array}$ \\
\hline $\begin{array}{l}\text { Masters Nursing } \\
\text { Masters Midwifery }\end{array}$ & $\begin{array}{l}23 \\
23\end{array}$ & $\begin{array}{l}9 \\
5\end{array}$ & $\begin{array}{r}13 \\
6\end{array}$ & $\begin{array}{l}62 \\
50\end{array}$ & $\begin{array}{l}73 \\
50\end{array}$ & $\begin{array}{l}0 \\
-\end{array}$ \\
\hline $\begin{array}{l}\text { Doctorate Nursing or } \\
\text { Midwifery }\end{array}$ & 40.5 & 3 & 5 & 80 & 80 & - \\
\hline
\end{tabular}


Accreditation was lower among non-public nursing diploma (24\%) and degree (33\%) programs compared to public nursing diploma (44\%) and degree (58\%) programs. While midwifery programs only represented $14 \%$ of the active programs, a higher percent of midwifery programs were accredited at the certificate (100\%) and diploma (91\%) levels.

Countries were asked to rate whether or not certain issues were challenges to them in carrying out accreditation processes (Fig. 2). Nine of the countries (56\%) reported limited financial resources to coordinate or carry out accreditation site visits as a serious challenge. Seven countries (44\%) reported limited human, material, and technical expertise related to accreditation inspections as key challenges. Six countries (38\%) noted challenges due to the cost to the program being accredited, and five countries (31\%) identified limited experience of the accrediting body and no consistent review of the accreditation process. As for key considerations for accreditation from WHO, 14 countries (87\%) reported there were no challenges with national legislation or transparency in the accreditation process and 15 countries (94\%) reported no challenges with their authority to accredit non-public institutions or competition among stakeholders.

The guidelines also recommended that accreditation be transparent and the process be evaluated periodically [11]. Issues of transparency included stakeholder engagement, self-assessment, evaluation feedback, and public disclosure. Thirteen countries (81\%) considered stakeholder input when establishing the national accreditation standards and process, 16 countries (100\%) utilized a self-assessment, 15 countries (94\%) provided feedback to the institution concerning their accreditation evaluation, and 10 countries (63\%) disclosed schools' and programs' accreditation status to the public, indicating higher levels of transparency in the establishment of accreditation standards and feedback to institutions under review than in public disclosure of institutions' accreditation results. Eleven countries (69\%) reported that they regularly reviewed their standards and process for accreditation, highlighting the need for more routine reviews of national accreditation systems.

\section{Discussion}

This study provided a baseline assessment of nursing and midwifery pre-service education accreditation in 16 countries in the ECSA region with respect to the $2013 \mathrm{WHO}$ guidelines [11]. The guidelines recommended strengthening health professional accreditation supported by legislation [11]. Fifteen of the 16 ECSA countries surveyed (94\%) mandate accreditation of pre-service education, which is a higher percentage than the global estimate of $50 \%$. Two of the essential components of an accreditation process are met to a high degree, including self-assessments required by all 16 countries (100\%) and external reviews in 15 countries (94\%). However, even though most countries mandate accreditation, only $35 \%$ of the 131 diploma nursing programs, which produce the majority of the nursing workforce in the ECSA region [15], are accredited. The percent accreditation is stronger for public nursing diploma (44\%) and degree (58\%) programs compared to nonpublic nursing diploma (24\%) and degree (33\%) programs. Until countries are able to increase the percentage of diploma programs that are accredited, especially at nonpublic schools, it will be difficult to ensure these students receive a consistent, high quality education.

The WHO guidelines recommend accreditation be based on standards and done independently [11]. Twelve countries (75\%) reported that their accreditation process is based on national, regional, or international standards,

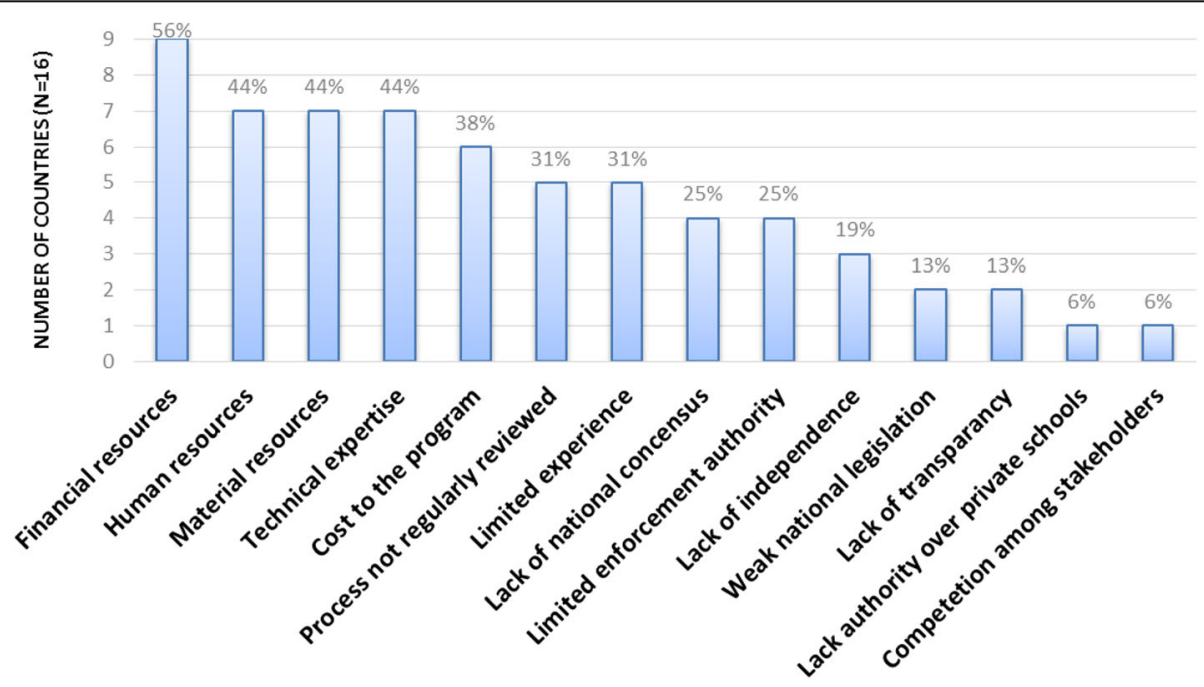

Fig. 2 Most frequently cited challenges to expanding accreditation, 2013 
or a combination thereof. Five countries (31\%) do not require the use of external board review and only seven countries (44\%) enforce routine renewal of accreditation for pre-service training programs-steps countries could incorporate to enhance accreditation. While seven countries (44\%) use a body other than the nursing council as the accrediting body, the role of the nursing council in accreditation should be evaluated to ensure its professional contribution to the accreditation of nursing and midwifery programs, which is often mandated in the national nursing act. In instances where the council is not the direct accrediting body, councils could consider providing technical tools for institutional self-assessments, external inspection score cards, and guidelines for routine accreditation renewal among other guidance to the accrediting bodies. Nine countries (56\%) noted financial challenges, and seven (44\%) identified challenges with human, material, and technical resources. Administration fees charged to institutions and programs undergoing the accreditation process can be utilized to garner additional resources, which could continue to increase as routine accreditation renewals are expanded, to support strengthening the accreditation process.

Despite the recent focus on and support for health professional training in low- and middle-income countries [15-17], many in sub-Saharan Africa still face substantial challenges to producing a higher quantity, quality, and relevance of health professionals, particularly given high levels of health professional migration, proliferation of private and for-profit educational institutions, and dynamic population health needs $[1,18-20]$. Substantial gaps in the number of faculty, quality of curricula, health professional regulation, and available resources will likely make meeting the new accreditation recommendations difficult $[9,15,21,22]$. The 2015 PEPFAR human resources for health strategy calls for an "adequate supply and quality of human resources for health to expand HIV/AIDS services," highlighting the need for periodic review of pre-service training curricula as a part of the accreditation review process [20]. The WHO Global Strategy on Human Resources for Health: Workforce 2030 made accreditation a key global milestone; countries must report annually on the presence of established accreditation mechanisms for health training institutions [9]. Particularly pertinent to our study sample, Workforce 2030 also recommends that health professional regulatory councils institute greater oversight of accreditation activities.

The limitations of this study include the biases intrinsic in self-report surveys, including recall bias and social desirability bias. This study also used convenience sampling, which may not represent the entire population of interest. In addition, questions did not address a main recommendation within the WHO guidelines: whether or not the government was currently supporting efforts to develop or strengthen accreditation systems. Lastly, this study was conducted in late 2013, and certain elements of countrylevel education or accreditation may have changed since the data were collected. Despite the limitations, the findings of this study will be particularly relevant in the African region, where the $\mathrm{WHO}$ regional office has embarked on the development of prototype curricula for pre-service nursing and midwifery programs [21], as well as a regional professional regulatory framework [22]. The information from this study should be useful as these tools are piloted in the Africa region. Furthermore, the study establishes a baseline of countries' pre-service education accreditation systems and provides a benchmark from which to measure progress towards global milestones set by WHO for 2020 and 2030.

\section{Conclusion}

The process of accreditation can certify to what extent schools responsible for educating health professionals meet quality standards to ensure graduates obtain core competencies [14]. This study of nursing and midwifery pre-service accreditation in 16 sub-Saharan African countries presents a description of current policies, practices, and approaches relative to the $2013 \mathrm{WHO}$ guidelines to strengthen health professional education for the new century. Efforts to strengthen accreditation for nursing and midwifery pre-service training institutions should focus on reviewing countries' national accreditation process and standards, utilizing an external board review in the process, increasing accreditation for diploma programs and private programs, and enforcing routine renewal of programs' accreditation status. Given the challenging context in which countries are striving to meet the ambitious global milestones set by Workforce 2030, targets to improve accreditation will require increasingly coordinated policy investments in the health workforce nationally and globally.

\section{Additional file}

Additional file 1: Accreditation survey tool. (DOCX $268 \mathrm{~kb}$ )

\section{Abbreviations}

ARC: African Health Professions Regulatory Collaborative; ART: Antiretroviral therapy; ECSA: East, Central, and Southern Africa; HIV/AIDS: Human immunodeficiency virus/acquired immune deficiency syndrome; PEPFAR: President's Emergency Plan for AIDS Relief; WFME: World Federation for Medical Education; WHO: World Health Organization

\section{Acknowledgements}

The authors would like to acknowledge all country nursing leadership teams for their contributions to this descriptive survey and for their dedication and work to ensure progress on their grants, as well as the support provided by CDC country offices' staff to national nursing leaders as they worked to advance nursing regulations in their respective countries. 


\section{Funding}

This study was supported under a cooperative agreement from the Centers for Disease Control and Prevention (CDC) through the Association of Schools and Programs of Public Health (ASPPH) grant number 1U36OE000002, project number S5033. The contents of this article are solely the responsibility of the authors and do not necessarily represent the official views of CDC or ASPPH.

\section{Availability of data and materials}

All data and materials are available upon request; study instruments are included as additional materials.

\section{Authors' contributions}

CFM conceived the study, led data collection, and conducted data analysis. CFM and JMG drafted and revised the article. JMG conducted data analysis and interpretation. ARV participated in the data collection and drafting the article. ELW, AMN, and TJL critically revised the article for content. MAK provided final review and approval of the version to be published. All authors read and approved the final manuscript.

\section{Ethics approval and consent to participate}

The US Centers for Disease Control and Prevention reviewed and approved the study protocol. All participants were provided a detailed Study Information Sheet with all relevant information to provide consent. Participation in the study was considered providing informed consent.

\section{Consent for publication}

All participants consented to the publication of study results at the time the survey was administered.

\section{Competing interests}

The authors declare that they have no competing interests.

\section{Publisher's Note}

Springer Nature remains neutral with regard to jurisdictional claims in published maps and institutional affiliations.

\section{Author details \\ ${ }^{1}$ Health Systems and Human Resources Team, Division of Global HIV/TB, U.S. Centers for Disease Control and Prevention, Atlanta, GA, United States of America. ${ }^{2}$ Health Workforce Department, World Health Organization, Geneva, Switzerland. ${ }^{3}$ Pan American Health Organization, World Health Organization, St. Michael, Barbados. "Monitoring, Evaluation, Investigations and Research, Nurses and Midwives Council of Malawi, Lilongwe, Malawi. ${ }^{5}$ Emory University's Nell Hodgson Woodruff School of Nursing, Atlanta, GA, United States of America.}

Received: 19 April 2017 Accepted: 11 July 2017

Published online: 24 July 2017

\section{References}

1. World Health Assembly, WHA 59.23: Rapid scaling of health workforce production. 2006, World Health Organization. http://www.who.int/hrh/ resources/WHA_59-23_EN.pdf?ua=1. Accessed 7 Sept 2015.

2. World Health Organization, Report on the WHO/PEPFAR planning meeting on scaling up nursing and medical education. 2009, http://www. hrhresourcecenter.org/node/2979. Accessed 7 Sept 2015.

3. Palen J, El-Sadr W, Phoya A, Imtiaz R, Einterz R, Quain E, et al. PEPFAR, health system strengthening, and promoting sustainability and country ownership. J Acquir Immune Defic Syndr. 2012;60(Suppl 3):S113-9.

4. Mullan F, Frehywot S, Omaswa F, Buch E, Chen C, Greysen SR, et al. Medical schools in sub-Saharan Africa. Lancet. 2011;377(9771):1113-21.

5. Faul, M., US funding to train 140,000 African health workers, in The Washington Times; 2011. http://www.washingtontimes.com/news/2011/mar/ 8/us-funding-to-train-140000-african-health-workers/. Accessed 7 Sept 2015.

6. World Health Organization. World Health Assembly, WHA Resolution 66.23: Transforming health workforce education in support of universal health coverage; 2013. http://apps.who.int/gb/ebwha/pdf_files/WHA66/A66_R23-en.pdf?ua=1. Accessed 7 Sept 2015

7. World Health Organization and The World Bank, Monitoring progress towards universal health coverage at country and global levels: a framework. Joint WHO/World Bank Discussion Paper. 2013. WHO/World
Bank Group. http://www.who.int/healthinfo/country_monitoring_ evaluation/UHC WBG_DiscussionPaper_Dec2013.pdf. Accessed 7 Sept 2015.

8. Frenk J, Chen L, Bhutta ZA, Cohen J, Crisp N, Evans T, et al. Health professionals for a new century: transforming education to strengthen health systems in an interdependent world. Lancet. 2010;376(9756):1923-58.

9. World Health Organization, Global strategy on human resources for health: Workforce 2030. 2016

10. World Federation for Medical Education, Promotion of accreditation of basic medical education: a programme within the framework of the WHO/WFME strategic partnership to improve medical education. 2005. http://wfme.org/ accreditation/whowfme-policy/30-1-promotion-of-accreditation-of-basicmedical-education-who-wfme-strategic-partnership/file. Accessed 7 Sept 2015.

11. World Health Organization, Transforming and scaling up health professionals education and training: World Health Organization guidelines; 2013. http://whoeducationguidelines.org/sites/default/files/uploads/ WHO_EduGuidelines_20131202_high_print.pdf. Accessed 7 Sept 2015.

12. World Health Organization, Transformative scale up of health professional education: an effort to increase the numbers of health professionals and to strengthen their impact on population health. 2011, http:/apps.who.int/iris/bitstream/10665/70573/1/ WHO_HSS_HRH_HEP2011.01_eng.pdf. Accessed 7 Sept 2015.

13. Boelen C, Woollard B. Social accountability and accreditation: a new frontier for educational institutions. Med Educ. 2009:43(9):887-94.

14. Uys $L$, Coetzee $L$. Transforming and scaling up health professional education and training: policy brief on accreditation of institutions for health professional education. 2013. World Health Organization http:// whoeducationguidelines.org/sites/default/files/uploads/whoeduguidelines_ PolicyBrief_Accreditation.pdf. Accessed 7 Sept 2015.

15. Klopper $H$, Uys $L$. The state of nursing and nursing education in Africa: a country-by-country review. Indianapolis: Sigma Thete Tau International; 2013.

16. McCarthy CF, Riley PL. The African Health Profession Regulatory Collaborative for nurses and midwives. Hum Resour Health. 2012;10:26.

17. McCarthy CF, Zuber A, Kelley MA, Verani AR, Riley PL. The African Health Profession Regulatory Collaborative (ARC) at two years. Afr J Midwifery Womens Health. 2014:8(2):4-5.

18. Gross JM, Kelley MA, McCarthy CF. A model for advancing professional nursing regulation: the African Health Profession Regulatory Collaborative. J Nurs Regul. 2015;6(3):29-33.

19. World Health Organization. Health workforce: density of nursing and midwifery personnel (total per 1000 population). 2015. Available from: http://gamapserver.who.int/gho/interactive_charts/health_workforce/ NursingMidwiferyDensity/atlas.html. Accessed 7 Sept 2015.

20. PEPFAR Human Resources for Health Strategy, PEPFAR 3.0. 2015. http://www.pepfar.gov/about/strategy/237172.htm. Accessed 7 Sept 2015.

21. WHO Regional Office for Africa, Four-year integrated nursing and midwifery competency-based, prototype curriculum for the African Region 2013. 2014. Brazzaville: World Health Organization. http://apps.who.int/iris/bitstream/ 10665/254742/1/9789290232612-eng.pdf.

22. WHO Regional Office for Africa, The regional professional regulatory framework for nursing and midwifery: creating a common approach to regulation, educational preparation and practice: future direction for nursing and midwifery development in the Africa region. 2014, Brazzaville: World Health Organization.

\section{Submit your next manuscript to BioMed Central and we will help you at every step:}

- We accept pre-submission inquiries

- Our selector tool helps you to find the most relevant journal

- We provide round the clock customer support

- Convenient online submission

- Thorough peer review

- Inclusion in PubMed and all major indexing services

- Maximum visibility for your research

Submit your manuscript at www.biomedcentral.com/submit
) Biomed Central 